\title{
Psychological factors of sibling caregivers of patients with severe mental disorders: an observational study
}

\author{
Francesca Pierazzuoli, ${ }^{1}$ Elisa Gatti, ${ }^{2}$ Maria Rosa Castelli, ${ }^{1}$ Giuseppe Primerano,,${ }^{1}$ Osmano Oasi, ${ }^{3}$ Giacomo Tognasso, ${ }^{2}$ \\ Livio Finos, ${ }^{4}$ Alessandra Santona ${ }^{2}$ \\ ${ }^{1}$ Department of Mental Health, Asst Bergamo Ovest, Bergamo; ${ }^{2}$ Department of Psychology, University of Milano-Bicocca, Milan; \\ ${ }^{3}$ Department of Psychology, Catholic University of the Sacred Heart, Milan; ${ }^{4}$ Department of Developmental Psychology and Socialisation, \\ University of Padua, Italy
}

\begin{abstract}
The goal of the present study is to explore the perception of the relationship with parental figures, traumatic experiences, personality traits and psychosocial characteristics of the participant sibling caregivers. The sample was composed of 30 sibling caregivers recruited at psychiatric facilities in Italy, and of 30 control siblings. The battery of instruments administered included Parental Bonding Instrument (PBI), Minnesota Multiphasic Personality Inventory 2 (MMPI-2), and The Inventory of Traumatic Experiences (TEC). This research found that sibling caregivers of patients with severe psychiatric pathologies are distinctly different from the siblings of the control group with respect to the perception of their relationship with parental figures more frequently regarded as dysfunctional, and were also characterized by a higher presence of traumatic experiences. The problematic relationship with parental figures, some traumatic experiences, and the burden of taking care of a sibling with psychiatric disorders are probably important variables with regards to the individual's overall psychological condition.
\end{abstract}

Key words: Caregiver; Mental health; Parental relationship; Traumatic experiences; Personality characteristics.

\section{Introduction}

Family caregivers of individuals with severe mental disorders are extremely important for effective treatment since caregivers help to maintain medical and psychosocial continuity between various providers. Historically,

Correspondence: Giacomo Tognasso, Department of Psychology, University of Milano-Bicocca, Milan, Italy.

E-mail: g.tognasso@campus.unimib.it

Citation: Pierazzuoli, F., Gatti, E., Castelli, M.R., Primerano, G., Oasi, O., \& Tognasso, G., Finos, L., \& Santona, A. (2020). Psychological factors of sibling caregivers of patients with severe mental disorders: an observational study. Research in Psychotherapy: Psychopathology, Process and Outcome, 23(1), 67-76. doi: 10.4081/ripppo.2020.412

Conflict of interests: The research was conducted in the absence of any commercial or financial relationships that could be construed as a potential conflict of interest.

Received for publication: 3 July 2019.

Accepted for publication: 24 February 2020.

This work is licensed under a Creative Commons Attribution NonCommercial 4.0 License (CC BY-NC 4.0).

${ }^{\circ}$ Copyright: the Author(s), 2020

Licensee PAGEPress, Italy

Research in Psychotherapy:

Psychopathology, Process and Outcome 2020; 23:67-76

doi:10.4081/ripppo.2020.412 caregivers were primarily parental figures, especially mothers (Caqueo-Urízar, Gutiérrez-Maldonado, \& Miranda-Castillo, 2009), while the current trend is that other family members and often siblings are more likely to take on this role (Amaresha, Venkatasubramanian, \& Muralidahr, 2014; Greenberg, Seltzer, \& Orsmond, 1999; Horwitz, Reinhard, \& Howell-White, 1996).

Taking the role of primary caregiver ${ }^{1}$ for a sibling with a severe mental disorders has been found to be influenced by several factors: the gender of the caregiver (Horwitz, Tessler, \& Fisher, 1992), onset of the psychiatric disorder (Rajji, Ismail, \& Mulsant, 2009), sense of family duty, relationship quality, reciprocity and benefits, ability to control symptoms, personal situation, perception of control and self-efficacy, as well as moral obligations and personal habits of the caregiving sibling (Bandura, 1982; Eagly \& Chaiken, 1993). Various studies have investigated the wellbeing of caregivers (Awad \& Voruganti, 2008; CaqueoUrízar et al., 2009; Glozman, 2004; Grandón, Jenaro, \& Lemos, 2008; Horwitz et al., 1996; Provencher \& Fincham, 2000; Sin, Murrells, Spain, Norman, \& Henderson, 2016; Wong, Lam, Chan, \& Chan, 2012) and of siblings (Appels, 2004; Arajärvi et al., 2006; Argyropoulos et al., 2008; Barak \& Solomon, 2005; Friedrich, Lively, \& Buckwalter, 1999; Greenberg et al., 1999; Hatfield \& Lefley, 2005; Horwitz

\footnotetext{
From now on we will use the term 'caregiver' referring to a brother or a sister that takes care of a sibling with mental illness.
} 
et al, 1992; Nechmad et al., 2000; Smith, Greenberg, \& Seltzer, 2007; Stalberg, Ekerwald, \& Hultman, 2004; Taylor, Fuggle \& Charman, 2001) of individuals with a severe mental disease. On the other hand, the psychological characteristics, the parental styles models and the traumatic experiences during childood of sibling caregivers of patients with schizophrenia spectrum disorders, have undergone limited investigation. (Kallert \& Nitsche, 2008; Provencher \& Fincham, 2000; Roncone, Mazza, Ussorio, \& Pollice, 2007). In fact, the stressful experience of being the caregiver of a sibling with a severe mental disorder influences the psychological well-being of the caregiver himself. Caregivers of siblings with severe mental disorders often report a fear of developing a mental illness, as well as passing it on to their children (Amaresha et al., 2014; Appels, 2004; Nechmad et al., 2000; Sin, et al., 2016; Stalberg et al., 2004). Those fears are justified as sibling caregivers are at increased risk of developing a mental illness and/or have already developed psychological problems (Kendler, 1996).

Given the importance of caregivers for the lives of individuals with severe mental disorders, the quality of life of these individuals is, perhaps not surprisingly, strongly associated with the quality of relationship with their healthy siblings (Sin, Jordan, Barley, Henderson, \& Norman, 2015; Smith \& Greenberg, 2007), caregiver involvement, and future care expectations (Greenberg et al., 1999; Hatfield \& Lefley, 2005; Horwitz et al., 1992; Smith \& Greenberg, 2007; Smith et al., 2007). The impact of assuming the role of primary caregivers has shown that it brings about high levels of psychological stress (Richieri et al., 2011; Sin et al., 2016; Stalberg et al., 2004) as well as negatively impacting the caregiver's quality of life (Caqueo-Urizar et al., 2009; Martens \& Addington, 2001; Sin et al., 2015). It has also been associated with an increase in chronic diseases, psychosomatic symptoms, anxiety and depression (Arajärvi et al., 2006; Argyropoulos et al., 2008; Awad \& Voruganti, 2008; Friedrich et al., 1999; Glozman, 2004; Reiss, Neiderhiser, Hetherington, \& Plomin, 2000; Reiss \& Olivieri, 1991; Sin et al., 2016). Finally, primary caregivers have been shown to present high levels of objective and subjective burden, feelings of guilt, stigma, shyness (Barak \& Solomon, 2005; Sin et al., 2016), as well as lack of communication in the path of hyper-care of the sick sibling (Taylor et al., 2001), and widespread difficulties at a psychosocial level (Smith \& Greenberg, 2007; Smith et al., 2007). These findings not only highlight the need for carerspecific interventions (Sin et al., 2015; Sin et al., 2016), but also stress the intense involvement of caregivers in the therapeutic and rehabilitative needs of their psychopathological siblings (Dixon, Lyles, \& Scott, 1999; Marsh, Appleby, Dickens, Owens, \& Young, 1993; Sin et al., 2015).

The goal of the present research was to examine some psychological characteristics of caregivers of a sibling with a severe mental disorder. To do this we explored the perception of their relationship with parental figures, traumatic experiences and personality characteristics.
Our work hypothesis was that in comparison with the control group the group of siblings of patients with severe mental disorders was more likely to present: relationship difficulties with parental figures; family-related traumatic experiences; presence of psychopathological personality characteristics.

\section{Methods}

\section{Participants}

Given the difficulty of finding a clinical sample, thirty sibling caregivers were recruited on a voluntary basis at psychiatric facilities and psychiatric patient family associations in Lombardy (Italy), while thirty participants of the control group were recruited on a voluntary basis among the normal population with a snowball sampling. The inclusion criteria used for the sibling caregivers were the following: to be the primary caregivers, not to be living with the psychiatric sibling, absence of cognitive deficits and had to be above 18 years of age. Additionally, the following inclusion criteria were used for the psychiatric sibling: presence of a major psychiatric disorder (schizophrenia spectrum) for at least three years; receiving psychiatric treatment; previous hospitalization(s) in a psychiatric ward; absence of cognitive deficits; above 18 years of age. According to Grandón et al. (2008), we refer to primary caregivers as the member of the family who is most involved with the care of the psychiatric sibling.

Twenty-five caregivers were women $(M=51.4$ years old; range: 36-63) and 23 psychiatric siblings were male. The age difference between siblings in most cases was less than 8 years (26 participants in the group of caregivers and 21 participants in the control group) with 24 caregivers being older than their sibling. A significant number of participants had three or more siblings (12 in the group of caregivers and 10 in the control group). Psychiatric illness onset occurred before 30 years of age, 26 subjects with a diagnosis of schizophrenia spectrum disorder, of which 23 were diagnosed with schizophrenia and 28 were following a drug therapy.

Control group subjects were enrolled in such a way that the two resulting groups (i.e. sibling caregivers and control) were approximately balanced in terms of gender and age. Furthermore, the subjects of the control group had to have a supporting role within the sibship. Due to enrolling criteria, the proportion of females in the control group matched that of the caregivers, and the results in terms of age were also very similar ( $M=53$ years old; range: $37-65)$.

\section{Measures}

The battery of instruments administered to the two groups included:

- Parental Bonding Instrument (PBI) to assess the perception of the relationship with parental figures, both 
mother and father (Bonaiuto, Parrucchini, \& Pierro, 1997; Parker, Tupling, \& Brown, 1979). Originally the PBI was developed to measure two different dimensions: The 'care' dimension that evaluates the parental style on a continuum from coldness and neglect to affection and emotional warmth and the 'overprotection' dimension that evaluates the parental style on a continuum from independence to control and intrusion. As suggested by Gilbert, Allan and Goss (1996), we decided to use also the 'devaluation' dimension, that assesses the tendency of parents to debase and humiliate the child and the 'favouritism' dimension, that assesses the tendency to favour brothers or sisters to the detriment of the subject.

- Minnesota Multiphasic Personality Inventory 2 (MMPI-2) for the evaluation of personality characteristics (Hathaway \& McKinley, 1995). The MMPI-2 is one of the most used measures to assess general psychopathology. It is composed of 567 "True" or "False" items. The instrument is divided in three different groups of scales: 'Validity' indicators, 'Clinical' scales and 'Content' scales. We decided to use primarily the clinical scales that - with scores above 65 - could represent attributable symptoms due to the presence of severe psychopathology: Hyphocondriasis, Depression, Hysteria, Psychopathic deviation, Masculinity/Femmininity, Paranoia, Psychastenia, Schizophrenia, Hypomania, Social Introversion. In this study we decided to present only the clinical subscales of MMPI-2 because of their higher reliability in identifying psychopathological characteristics of personality.

- Trauma Experience Checklist (TEC), which investigates the presence of traumatic experiences in different contexts throughout the life cycle (Nijenhuis, van der Hart, \& Kruger, 2002). The TEC is a self-report measure addressing 29 potentially traumatizing events (e.g. the loss of parental figures, the presence of Parentification, war experiences). The instrument is divided in three subscales: Emotive Trauma, Sexual Trauma and Physical Threat. Anamnestic questionnaire that included questions regarding participants' personal data, marital status, family composition, characteristics and perception of the illness, characteristics of the relationship between siblings.

\section{Procedure}

For this study, a battery of self-reports was administered to the caregiver group and to the control group.

Due to limited sample size and lack of assumption of normality, the data was analyzed using a permutation (i.e. nonparametric) approach (Pesarin, 2001). For each test, the data are randomly permuted 10,000 times and the $t$ test statistic are computed for each permutation. The significance level is set to alpha $=0.05$. The PBI scales were analysed in accordance to the following schema. For each scale of the test the two groups were compared using sex and age as nuisance covariates. The permutations are based on orthogonalized residuals of the space spanned by the two covariates (Solari, Finos, \& Goeman, 2014). The p-values were corrected for multiplicity using a minp method (Westfall \& Young, 1993). In order to quantify he nett difference between the two groups (i.e. effect size purified from confounders sex and age), the partial correlation is reported.

Finally, with merely descriptive purposes, a Principal Component Analysis (PCA) was performed on a correlation matrix. The biplot reports the four combinations of sex and group in order to visually highlight the results of the inferential analysis. The TEC and MMPI scale were analysed following the same schema. The loadings used to draw the arrow in the biplot are also reported in the appendix.

Environmental characteristics and trauma experiences were analysed via Fisher's exact test (i.e. nonparametric). No multiple correction methods were used since the conclusion will be included with a purely descriptive intent. All the analyses have been developed with the $\mathrm{R}$ language (Team, 2013). In particular, the permutation-based analysis was made using the package flip (Finos, 2014), while the biplots are drawn using the package ggbiplot (Vu, 2011).

The study complied with the American Psychological Association (APA) ethical standards in the treatment of human research participants and conformed to the provisions of the Declaration of Helsinki in 1995 (revised in Edinburgh in 2000).

\section{Results}

\section{Perception of the relationship with parental figures (PBI)}

Comparing caregivers to the control group, statistically significant differences emerged with regard to the perception of maternal 'care', which was lower in the caregiver group. The scale of maternal 'favouritism', as well as maternal 'devaluation' was higher for the caregiver group (Table 1).

With respect to the perceived relationship with the father, caregivers did not differ significantly from the control group.

The results of PCA for PBI is reported in Figure 1.

The first and the second principal component explain $45.3 \%$ and $13.6 \%$ of total variance, respectively. The two experimental groups (i.e. female and male) show larger dispersion than control groups. The first principal components represent the 'Care' vs 'Devaluation', 'Overprotection' and 'Favoritism', while the second suggests a 'Maternal' vs 'Paternal' interpretation.

The directions of the arrow visually support the inferential results: the experimental groups show lower values in Maternal 'Care' (the arrow is far from the barycenter 
of the ellipses), while they have higher values in Maternal 'Favoritism' and Maternal 'Devaluation' (i.e. the arrows point to the left, where the experimental observations are located).

It is suggestive to see that the ellipse of Experimental Female is oriented toward the maternal scales, while the one of the Experimental Males toward the paternal ones.

\section{Traumatic experiences (TEC)}

Comparisons on several levels between the two groups were made, and the caregivers show the highest scores for several scales as can be seen in Table 2. In particular caregivers seemed to have higher scores in Emotional Trauma, Emotional Neglect, Emotional Abuse, Physical Abuse and in the Global scale.

The dichotomous items 1, 2, 13, 14, 17, 20 highlight some differences between the caregiver and control groups. Specifically, 53.3\% of caregiving participants compared to $10 \%$ of control group participants reported experience of parenting (item 1) [Fisher's exact test, $p=.001]$. Caregivers reported having had diverse family problems (item 2 ) in $66.7 \%$ of cases, compared with $3.3 \%$

Table 1. Differences between groups with respect to the steps of PBI.

\begin{tabular}{lcccc}
\hline Multivariate Analysis & Stat & Partial_rho & p-value & Adjust:minP \\
\hline Maternal Care & -3.3754 & -0.408 & 0.0017 & 0.0115 \\
\hline Maternal Overprotection & 1.6140 & 0.209 & 0.1135 & 0.3530 \\
\hline Maternal Favoritism & 4.9034 & 0.545 & 0.0001 & 0.0008 \\
\hline Maternal Devaluation & 2.8777 & 0.356 & 0.0069 & 0.0376 \\
\hline Paternal Care & -1.7019 & -0.220 & 0.0900 & 0.3334 \\
\hline Paternal Overprotection & 0.5852 & 0.077 & 0.5653 & 0.5966 \\
\hline Paternal Favoritism & 0.9228 & 0.121 & 0.3662 & 0.5966 \\
\hline Paternal Devaluation & 1.4626 & 0.190 & 0.1556 & 0.3734
\end{tabular}

${ }^{*} \mathrm{p}<0.05 ; * * \mathrm{p}<0.01 ; * * * \mathrm{p}<0.001$.

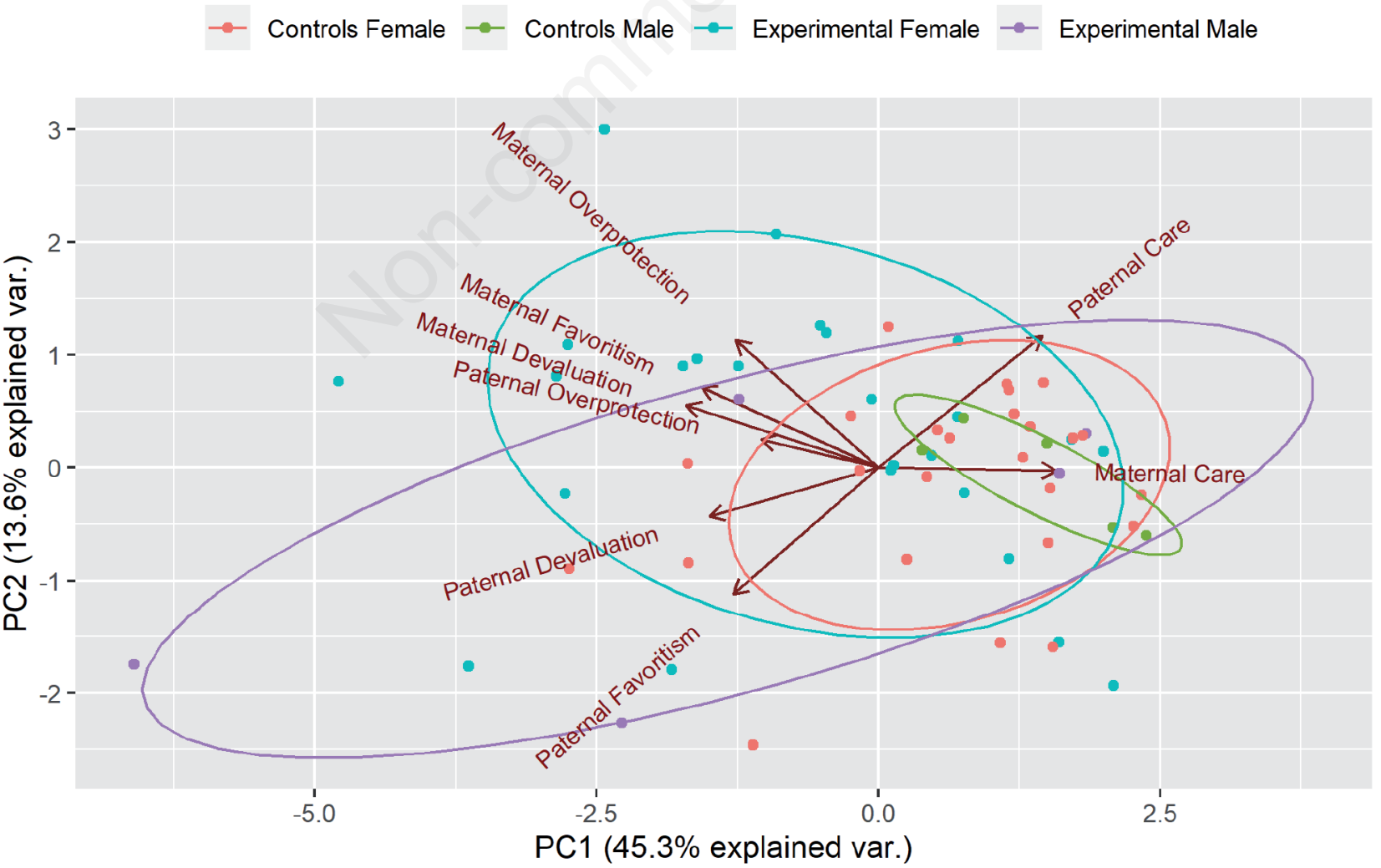

Figure 1. Principal Components Analysis for PBI. 
in the control group [Fisher's exact test, $p<.001]$. Caregivers reported having witnessed a trauma suffered by others (item 13) $56.7 \%$ of the time compared to $20 \%$ for the control group [Fisher's exact test, $p=.007$ ]. In addition, $50 \%$ of the caregivers reported emotional neglect by parents or siblings (item 14) and 30\% emotional neglect by extended family members (item 15 ), compared to $0 \%$ for the control group for both items [item 14: Fisher's exact, $p<.001$, item 15: Fisher's exact test, $p=.002]$. Emotional abuse by parents or siblings (item 17) was reported by $46.7 \%$ of the caregiver participants versus 3.3\% for control group participants [Fisher's exact test, $p<.001]$. In addition, physical abuse by parents or siblings (item 20) was reported by $23.3 \%$ of the caregiver participants compared to $0 \%$ for the control group participants [Fisher's exact test, $p=.011]$. For caregivers, $90 \%$ of them had suffered traumatic experiences within the family and for $54.17 \%$ of them this had occurred during childhood (under 12 years of age), while for the control group 59\% had a family traumatic experience with $32 \%$ occurring during childhood. With regards to age, duration, impact related to trauma, as well as to the reported abuser, no statistically significant differences between the two groups was found.

The results of PCA for TEC is reported in Figure 2.

The first and the second principal components explain $39.0 \%$ and $18.7 \%$ of total variance, respectively. Also, in this case, the two experimental groups (i.e. female and male) show larger dispersion than control groups. In this case it is suggestive to observe that the ellipse of experimental females is oriented toward the bundle of arrows of Sexual abuse, Sexual trauma and Sexual harassment, while the ellipse of experimental males is oriented toward Physical Abuse, Emotional Abuse and Physical Threat.

\section{Psychopathological features of personality (MMPI-2)}

As it can be seen in Table 3 the group of caregivers did not significantly differ from the control group in any psychopathological characteristics. The results of PCA for MMPI are reported in Figure 3.

The first and the second principal components explain $42.1 \%$ and $15.6 \%$ of total variance, respectively. The two groups of Female (i.e. Experimental and Control) broadly overlap, whereas there is a larger distance between 'Experimental' Males and 'Control' Males. In particular, the group of Experimental Males is oriented toward the higher values of symptoms.

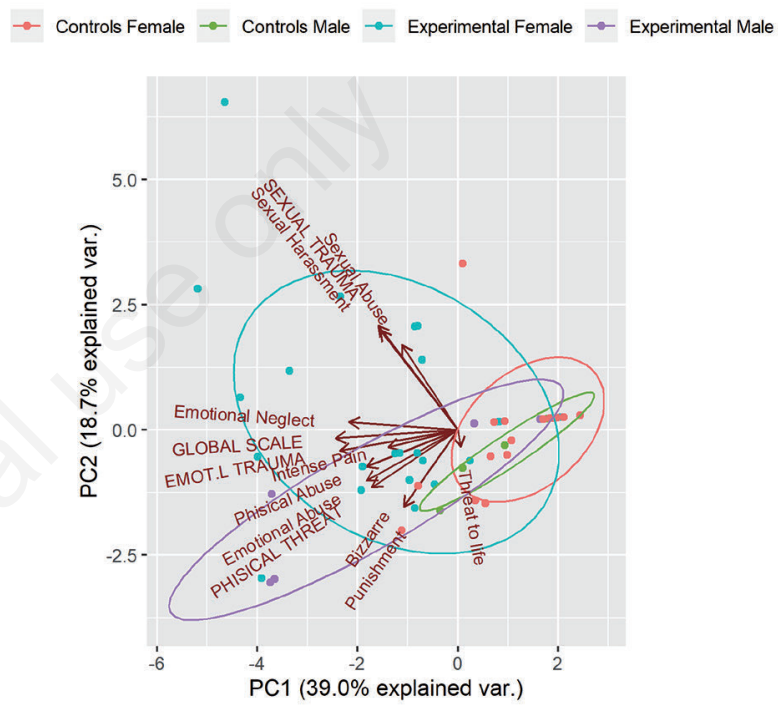

Figure 2. Principal Components Analysis for TEC.

Table 2. Differences between groups with respect to the steps of Tec.

\begin{tabular}{|c|c|c|c|c|c|}
\hline Multivariate Analysis & Stat & Partial_rho & p-value & Adjust:minP & Sig. \\
\hline Emotional Trauma & 6.1653 & 0.633 & 0.0001 & 0.0007 & $*$ \\
\hline Emotional Neglect & 5.9106 & 0.616 & 0.0001 & 0.0007 & $*$ \\
\hline Emotional Abuse & 3.7133 & 0.441 & 0.0004 & 0.0032 & $*$ \\
\hline Sexual Trauma & 2.0961 & 0.268 & 0.0416 & 0.1917 & \\
\hline Sexual Abuse & 1.3079 & 0.171 & 0.2065 & 0.5063 & \\
\hline Sexual Harassment & 2.1935 & 0.279 & 0.0335 & 0.1672 & \\
\hline Physical Threat & 1.6675 & 0.216 & 0.1050 & 0.3428 & \\
\hline Threat to life & -0.9831 & -0.129 & 0.3373 & 0.5063 & \\
\hline Intense Pain & 1.7269 & 0.223 & 0.0892 & 0.3350 & \\
\hline Physical Abuse & 3.2227 & 0.393 & 0.0042 & 0.0282 & $*$ \\
\hline Bizarre Punishment & 1.0628 & 0.139 & 0.2911 & 0.5063 & \\
\hline Global Scale & 6.7395 & 0.666 & 0.0001 & 0.0007 & $*$ \\
\hline
\end{tabular}

${ }^{*} \mathrm{p}<0.05 ; * * \mathrm{p}<0.01 ; *^{* * *} \mathrm{p}<0.001$. 


\section{Clinical and environmental characteristics}

Comparing family characteristics, caregivers had a high rate of family history of psychiatric disorders (89.7\%), of which $27 \%$ had schizophrenic spectrum dis- orders. In addition, $53.3 \%$ of them had at least another family member with mental health problems, and predominately through the maternal line. In contrast, in the control group only $10.3 \%$ indicated the presence of family history of mental illness in their family (anxiety or mood

Table 3. Differences between groups with respect to the steps of MMPI.

\begin{tabular}{lcccc}
\hline Multivariate Analysis & Stat & Partial_rho & p-value & Adjust:minP \\
\hline Hypochondriasis & 0.8697 & 0.114 & 0.3883 & 0.8646 \\
\hline Depression & 1.3935 & 0.182 & 0.1709 & 0.6219 \\
\hline Hysteria & 0.9290 & 0.122 & 0.3560 & 0.8646 \\
\hline Psychopathic Deviate & 2.0797 & 0.266 & 0.0437 & 0.2676 \\
\hline Masculinity/Femininity & 0.2447 & 0.032 & 0.8098 & 0.9420 \\
\hline Paranoia & 2.2063 & 0.280 & 0.0322 & 0.2267 \\
\hline Psychasthenia & 1.4233 & 0.185 & 0.1569 & 0.6219 \\
\hline Schizophrenia & 2.0229 & 0.259 & 0.0463 & 0.2676 \\
\hline Hypomania & 0.5156 & 0.068 & 0.6050 & 0.9398
\end{tabular}

${ }^{*} \mathrm{p}<0.05 ;{ }^{*} \mathrm{p}<0.01 ; * * \mathrm{p}<0.001$

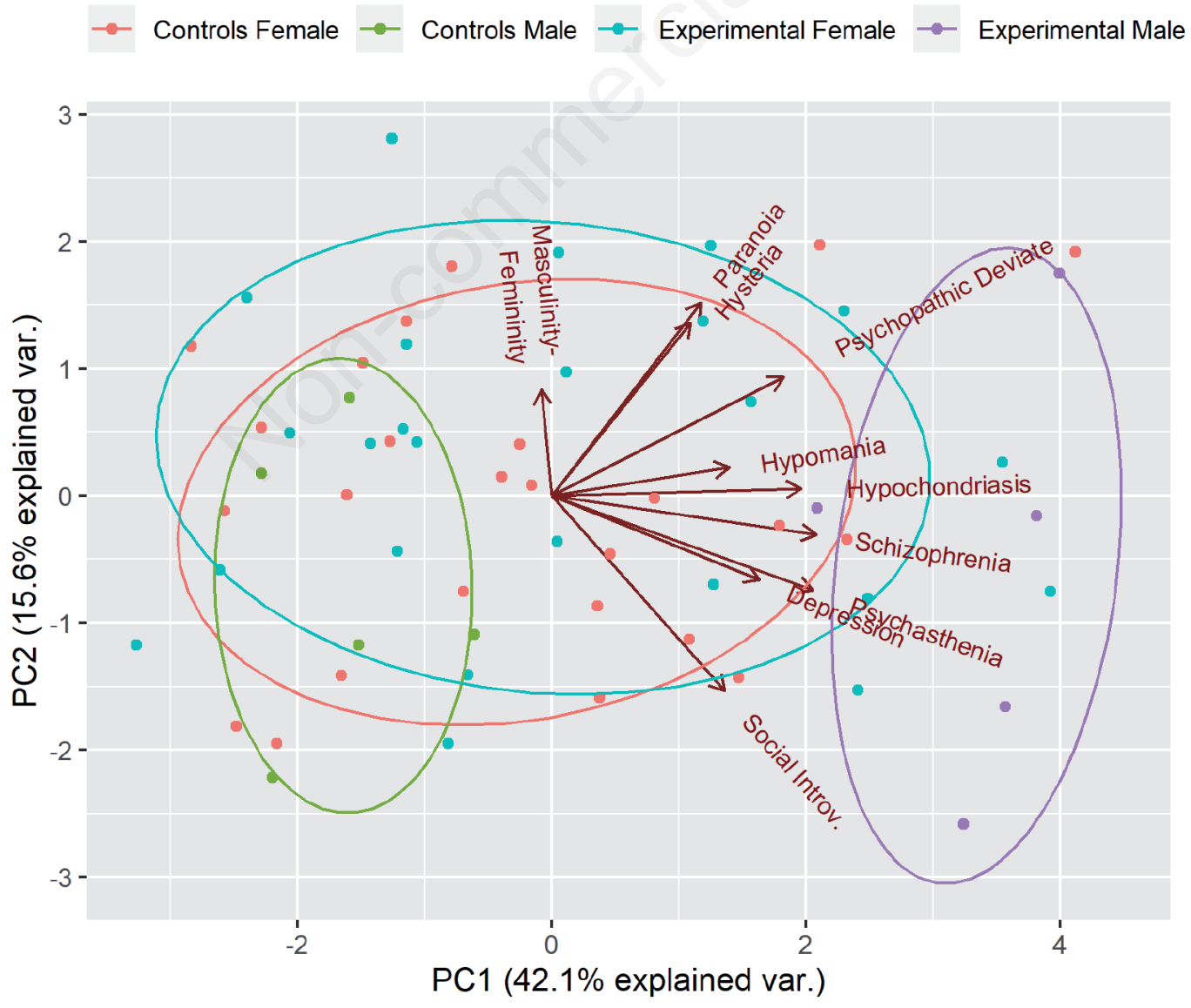

Figure 3. Principal Components Analysis for MMPI. 
disorders) [Fisher's exact test, $p<.001]$. For caregivers, $43.3 \%$ reported having previous psychological problems, mainly anxiety disorders, which differed from the control group, where none reported having had any [Fisher's exact test, $p<.001]$. Among caregivers, $65.4 \%$ of respondents indicated that they were afraid of developing a psychiatric condition, while only $30 \%$ of control group participants expressed this fear [Fisher's exact test, $p=.008]$. Among caregivers who had children, $94.4 \%$ said they were afraid that their children would develop a psychiatric condition, compared to $31.6 \%$ for the control group [Fisher's exact test, $p<.001]$. For caregivers, only $6.7 \%$ indicated having supportive family members, compared with $26.7 \%$ for the control group [Fisher's exact test, $p=.038]$.

For caregivers, $73.3 \%$ of them took on the role of caregiver for their psychiatric sibling before the death of their parents. The caregiver-psychiatric sibling relationship was described by most as being positive during childhood (66.7\%), as being positive prior to illness onset (70\%) and as being positive at present $(60 \%)$, and most of them $(57.1 \%)$ expected that the relationship will get better. Caregivers usually keep in contact with their sibling either on a daily or weekly basis (70\%).

Although most of the participants in the caregiver group made mention of a family environment characterized by many difficulties, none of them attributed the sibling's psychiatric illness to the environment itself. In fact, $83 \%$ of the caregivers attributed illness onset to a triggering event, such as enlisting in the military, the end of a relationship, or a specific problem at work. Most of the caregivers $(90 \%)$ reported that their sibling's illness had had a strong and negative impact on themselves and their families, in terms of perceived distress and burden.

\section{Discussion and Conclusions}

Our findings suggest that sibling primary caregivers of patients with severe psychiatric pathologies were markedly different from the siblings in the control group. They differed in terms of their perception of the relationship with parental figures and traumatic experiences but they did not differ compared to psychopathological characteristics.

With respect to the perception of parental relationships, for caregivers this was characterized by a lack of maternal care and, at the same time, by attitudes of maternal favouritism towards the other sibling and maternal devaluation (Table 1). An inspection of the biplot displayed in Figure 2 supports these results, also suggesting that females' caregivers are more oriented toward maternal-related negative parental experiences, and males toward paternal-related negative parental experiences.

Most of the caregiving group participants reported having traumatic experiences, in particular within the family environment during childhood and family prob- lems of different nature (alcoholism or psychopathology of a parent and economic difficulties), witnessing traumatic experiences of others, emotional neglect, emotional and physical abuse (Table 2). In fact, some psychological factors (e.g. Parentification) that seem to guide the caregiver's life, significantly influence the choice to assume the role of caregiver, as suggested by the frequent experience of parenting.

The dysfunctional attitude of the nurturing parent, mainly characterized by a lack of maternal care, comes from a type of traumatic experience such as, for example, neglect or emotional and physical abuse (Carli et al., 2019; Cassidy, 1994; Santona, De Cesare, Tognasso, De Franceschi, \& Sciandra, 2019). Despite these reported difficulties associated with the family environment (mostly related to a dysfunctional maternal attachment bond), almost no caregiver attributed the onset of the sibling's illness to these problems, considering some external cause instead. In fact, the majority of caregivers related their sibling's illness to some biological basis, like brain disease, or to other deficits like thinking disorders and character disorders (Gerace, Camilleri, \& Ayres, 1993). Caregivers were more likely to come from large families than control group participants, with almost half of the caregivers coming from a family with more than three siblings. Moreover, there was often a family history of psychiatric morbidity, mainly in the maternal line. The familiarity of psychiatric pathology detected in this research is similar to what has been reported by several studies in the literature (Albus \& Maier, 1995; Appels, 2004; Kendler, Thacker \& Wlash, 1996; Kendler et al., 1993; Maier et al., 2002; Tsuang, Stone, Tarbox \& Faraone, 2002; van Os, Linscott, Myin-Germeys, Delespaul, \& Krabbendam, 2009; Xinjun, Sundquista, Hemminkia, \& Sundquista, 2009). The relationship between siblings was defined as positive by most caregiver participants. Although the age difference between sibling and caregiver was less than eight years for the majority of the participants, there was often a "parental" relationship that began in early childhood (Santona \& Zavattini, 2005). Caregivers and their siblings were frequently emotionally as well as physically close and the perceived satisfaction was found to be high throughout the life cycle (childhood, premorbid period, present). In fact, fraternal relations do not seem to have changed much over time for caregivers, maintaining a good quality even after illness onset. This might be related to the fact that the caregiver role was reported as having started in childhood, as reported in our data and in literature (Coles, 2003; Horwitz, 1994; Horwitz et al., 1996; van der Kolk, McFarlane, \& Weisaeth, 2006). Caregivers reported being afraid of suffering from a psychiatric illness and having children that might suffer from one themselves, as already described in literature (Caqueo-Urizar et al., 2009; Martens \& Addington, 2001; Nechmad et al., 2000; Stalberg et al., 2004; Wong et al., 2012). Furthermore, other studies (Sin et al., 2016), sup- 
port that the burden of caring can cause clinically significant levels of distress for caregivers. It is important to underline that siblings' caregivers of patients with severe mental disorder have higher probability to develop a psychiatric illness due not only to the family environment but also to their shared genetic properties and to the distress linked to the role of primary caregiver.

Despite these findings, considering personality characteristics, in our study the group of caregivers did not significantly differ from the control group in psychopathological characteristics.

In conclusion, we found that dysfunctional relations with parental figures, traumatic experiences during childhood and load of caregiving seem to be common among caregivers of patients with severe mental disorders, in line with other studies' findings. It could thus be hypothesized that the presence of protective factors, such as certain personality traits (Bonanno, 2004; Pynoos, Steinberg, \& Piacentini, 1999; Rutter, 1985), relational experiences (Sander, 2007), or prevalence /absence of adaptive defence mechanisms (Calati, Oasi, De Ronchi, \& Serretti, 2010), help developing resilience in the caregiver. In fact, the occurrence of "a not shared" experience, as well as its subjective internal representations, can be considered as a key factor in the differences between siblings (Dunn \& Plomin, 1996).

If caregivers are essential figures and fully involved in the care of their sibling, difficulties encountered in the majority part of the sample with respect to negative relational experiences with the parental figures and the presence of traumatic experiences cannot be ignored since these caregivers need support in carrying out their duties. In this sense, taking care of a patient with a severe psychiatric disorder should not only aim at achieving patient rehabilitation, but also at taking care of the caregiver him/herself, as this is the individual who is managing the complexity of his/her sibling's illness. As shown in a review of literature (Westfall \& Young, 1993), primary caregivers have common needs in terms of information on their sibling's illness, and might benefit from support groups as well. Furthermore, specific attentions could be given to family of carers of individuals with recent onset psychosis.

Our study has several limitations. First of all, this is an observational study based on a case-control study and for this reason our findings can only be generalized to the particular population of siblings who are the primary caregivers and not to all siblings of a patient with schizophrenia spectrum disorder. Furthermore, the sample is unbalanced concerning gender, consequently we cannot draw definitive conclusions concerning gender differences.

Several questions remain open. While the present work includes a small sample size and doesn't include complete detailed amnestic information on non-caregiving family members, it does, on the other hand, provide evidence that makes it possible to draw conclusions on several variables that are influential for the psychological state of sibling caregivers. Future research should examine the characteristics of non-caregiving siblings as well as caregivers living with their sick sibling.

Furthermore, it is our hope that this study will trigger an increased interest in gaining a better understanding of the shift in caregiving from parents to siblings and draw the attention on the needed welfare support for this caregiver group.

\section{References}

Albus, M., \& Maier, W. (1995). Lack of gender differences in age at onset in familial schizophrenia. Schizophr Res 18:517.

Amaresha, A.C., Venkatasubramanian, G., \& Muralidahr, D. (2014). Needs of siblings of persons with psychosis: a systematic descriptive review. Clin Psychopharmacol Neurosci 12(2):111-23.

Appels, M. (2004). Elevated Level of schizotypal features in parents of patients with a family history of schizophrenia spectrum disorders. Schizophr Bull 30(4): 781-90.

Arajärvi, R., Ukkola, J., Haukka, J., Suvisaari, J., Hintikka, J., Partonen, T., \& Lönnqvist, J. (2006). Psychosis among "healthy" siblings of schizophrenia patients. BMC Psychiatr $J 6(6)$.

Argyropoulos, S.V, Landau, S., Kalidindi, S., Toulopoulou, T., Castle, D.J.,Murray, R.M., \& Picchioni, M.M. (2008). Twins discordant for schizophrenia: psychopathology of the nonschizophrenic co-twins. Acta Psychiatrica Scandinava 118(3): 214-9.

Awad, A.G., \& Voruganti, L.N. (2008). The burden of schizophrenia on caregivers: a review. PharmacoEconomics 26(2): 149-62.

Bandura, A. (1982). Psychology of chance encounters and life paths. American Psychologist, 37: 747-755.

Barak, D., \& Solomon, Z. (2005). In the shadow of schizophrenia: a study of siblings' perceptions. Israel J Psychiatr Related Sci 2005, 42(4):234-41.

Bonaiuto, M., Parrucchini, P., \& Pierro, A. (1997). [L'adolescente e i membri significativi della sua rete sociale. Qualità delle relazioni interpersonali.] Età Evolutiva, 57:40-56. [Article in Italian].

Bonanno, G. (2004). Loss, trauma and human resilience: Have we underestimated the human capacity to thrive after extremely aversive events? Am Psychologist 59(1): 20-8.

Calati, R., Oasi, O., De Ronchi, D., \& Serretti, A. (2010). The use of the defence style questionnaire in major depressive and panic disorders: A comprehensive meta-analysis. Psychol Psychother: Theory, Res Practice 83:1-13.

Caqueo-Urízar, A., Gutiérrez-Maldonado, J., \& MirandaCastillo, C. (2009). Quality of life in caregivers of patients with schizophrenia: a literature review. Health Quality Life Outcomes 11(7):84.

Carli, L.L., Anzelmo, E., Pozzi, S., Feeney, J., Gallucci, M., Santona, A., \& Tagini, A. (2019). Attachment Network Structure in Committed Couples. Frontiers in psychol 10:1105.

Cassidy, J. (1994). Emotion regulation: Influences of attachment relationships. In N.A. Fox (Ed.), The development of emotion regulation: Biological and behavioral considerations. Monographs of the Society for Research in Child Development, 59. (Serial No. 240). 
Coles, P. (2003). The Importance of Sibling Relationships in psychoanalysis. London: Karnac Book.

Dixon, L., Lyles, A., \& Scott, J. (1999). Services to families of adults with schizophrenia: from treatment recommendations to dissemination. Psychiatric Services, 50:233-38.

Dunn, J., \& Plomin, R. (1996). Sibling Relationships: Their Causes and Consequences. Westport CT: Praeger.

Eagly, A.H., \& Chaiken, S (1993): The psychology of attitudes. Orlando, FL: College Publishers.

Finos, L. (2014). flip: Multivariate Permutation Tests. R package version 2.4. 3 .

Friedrich, R.M., Lively, S., \& Buckwalter, K.C. (1999). Well siblings living with schizophrenia. Impact of associated behaviours. J Psychosoc Nursing Mental Health Services 37:11-9.

Gerace, L., M., Camilleri, D., \& Ayres, L. (1993). Sibling Perspectives on Schizophrenia and the Family. Schizophr Bull 19(3):637-47.

Gilbert, P., Allan, S., \& Goss, K. (1996). Parental representations, shame, interpersonal problems, and vulnerability to psychopathology. Clin Psychol Psychother 3(1):23-34

Glozman, J.M. (2004). Quality of life of caregivers. Neuropsychol Rev 14:183-96.

Grandón, P., Jenaro, C., \& Lemos, S. (2008). Primary Caregivers of Schizophrenia Outpatients: Burden and Predictor Variables. Psychiatr Res 158(3):335-43.

Greenberg, J.S., Seltzer, M.M., \& Orsmond, G.I. (1999). Siblings of adults with mental illness or mental retardation: current involvement and expectation of future caregiving. Psychiatr Serv 50: 1214-19.

Hatfield, A.B., \& Lefley, H.P. (2005). Future involvement of siblings in the lives of persons with mental illness. Community Ment Health J 41: 327-38.

Hathaway, S.R., \& McKinley, J.C. (1995). MMPI-2. Minnesota Multiphasic Personality Inventory-2 (Adattamento Italiano di Paolo Pancheri e Saulo Sirigatti). Firenze: Giunti O.S.

Horwitz, A.V. (1994). Predictors of adult sibling social support for the seriously mentally ill J Family Issues 15: 272-89.

Horwitz, A.V., Reinhard, S.C., \& Howell-White, S. (1996). Caregiving as reciprocal exchange in families with seriously mentally ill members. $J$ Health and Social Behav 37: 149-62.

Horwitz, A.V., Tessler, R.C., \& Fisher, G.A. (1992). The role of adult siblings in providing social support to the severely mentally ill. J Marriage and Family, 54: 233-41.

Kallert, T.W., \& Nitsche, I. (2008). Assessing the opinions of relatives on the causes and social consequences of different mental disorders: are instruments cross-culturally valid? Psychiatr Res 158(3): 344-55.

Kendler, K.S. (1996). Parenting: A genetic-epidemiologic perspective. Am J Psychiatr 153:11-20.

Kendler, K.S., McGuire, M., Gruenberg, A.M., O'Hare, A., Spellman, M., \& Walsh, D. (1993). The Roscommon Family Study. IV. Affective illness, anxiety disorders, and alcoholism in relatives. Archiv General Psychiatr 50(12):95260 .

Kendler, K.S., Thacker, L., \& Walsh, D. (1996). Self-report measures of schizotypy as indexes of familial vulnerability to schizophrenia. Schizophr Bull 22(3):511-20.

Maier, W., Lichtermann, D., Franke, P., Heun, R., Falkai, P., \& Rietschel, M. (2002). The dichotomy of schizophrenia and affective disorders in extended pedigrees. Schizophr Res 57(2-3): 259-66.

Marsh, D.T., Appleby, N.F., Dickens, R.M., Owens, M., \&
Young, N.O. (1993). Anguished voices: impact of mental illness on siblings and children. Innovat Res 2: 25-34.

Martens, L., \& Addington, J. (2001). The psychological wellbeing of family members of individuals with schizophrenia. Social Psychiatr Psychiatric Epidemiol 36(3):128-33.

Nechmad, A., Fenning, S., Ternochiano, S., Treves, I., FennigNaisberg, S., \& Levkovich, Y. (2000). Siblings of schizophrenic patients - a review. Israel J Psychiatr Related Sci 37: 3-11.

Nijenhuis, E.R.S., van der Hart, O., \& Kruger, K. (2002). The psychometric characteristics of the traumatic experiences checklist (TEC): First findings among psychiatric outpatients. Clin Psychol Psychother 9:200-10.

Parker, G., Tupling, H., \& Brown, L.B. (1979). Parental Bonding Instrument. British J Med Psychol 52:1-10.

Pesarin, F. (2001) Multivariate Permutation Tests: With Applications in Biostatistics. Wiley, Chichester.

Provencher, E., \& Fincham, F. (2000). Attributions of causality, responsibility and blame for positive and negative symptom behaviours in caregivers of persons with schizophrenia. Psychological Med 30(4):899-910.

Pynoos, R.S., Steinberg, A.M., \& Piacentini, J.C. (1999). A Developmental Psychopathology Model of Childhood Traumatic Stress and Intersection with Anxiety Disorders. Biological Psychiatr 46: 1542-54.

Rajji, T.K., Ismail, Z., \& Mulsant, B.H. (2009). Age at onset and cognition in schizophrenia: meta-analysis. British J Psychiatr 195(4): 286-93.

Reiss, D., \& Oliveri, M.E. (1991). The family's conception of accountability and competence: A new approach to the conceptualization and assessment of family stress. Family Process 30(2):193-214.

Reiss, D., Neiderhiser, J.H., Hetherington, E.M., \& Plomin, R. (2000). The Relationship Code. Harvard: University Press.

Richieri, R., Boyer, L., Reine, G., Loundou, A., Auquier, P., Lançone, C., \& Simeoni, M.C. (2011). The Schizophrenia Caregiver Quality of Life questionnaire (S-CGQoL): Development and validation of an instrument to measure quality of life of caregivers of individuals with schizophrenia. Schizophr Res 126: 192-201.

Roncone, R., Mazza, M., Ussorio, D., \& Pollice, R. (2007). The questionnaire of family functioning: a preliminary validation of a standardized instrument to evaluate psychoeducational family treatments. Comm Ment Health J 43(6): 591-607.

Rutter, M. (1985). Resiliency in the face of adversity. Protective factors and resistance to psychiatric disorders. British J Psychiatr 147:598-611.

Sander, L. (2007). Living Systems, Evolving Consciousness, and the Emerging Person: A Selection of Papers from the Life Work of Louis Sander. London: Routledge.

Santona, A., \& Zavattini, G.C. (2005). Partnering and parenting expectations in adoptive couple. Sexual and Relationship Ther 20(3):309-22.

Santona, A., De Cesare, P., Tognasso, G., De Franceschi, M., \& Sciandra, A. (2019). The mediating role of romantic attachment in the relationship between attachment to parents and aggression. Frontiers in Psychol 10, 1824.

Sin, J., Jordan, C.D., Barley, E.A., Henderson, C., \& Norman, I. (2015). Psychoeducation for siblings of people with severe mental illness. Cochrane Database of Systematic Rev $8 ;(5)$.

Sin, J., Murrells, T., Spain, D., Norman, I., \& Henderson, C. (2016). Wellbeing, mental health knowledge and caregiving 
experiences of siblings of people with psychosis, compared to their peers and parents: an exploratory study. Social Psychiatr Psychiatr Epidemiol 51(9):1247-55.

Smith, J., Greenberg, J.S., \& Seltzer, M.M. (2007). Siblings of Adults with Schizophrenia: Expectations About Future Caregiving Roles. Am J Orthopsychiatr 77(1): 29-37.

Smith, M.J., \& Greenberg, J.S. (2007). The effects of the quality of sibling relationships on the life satisfaction of adults with schizophrenia. Psychiatr Serv 58: 1222-24.

Solari, A., Finos, L., \& Goeman, J. J. (2014). Rotation-based multiple testing in the multivariate linear model. Biometrics 70(4), 954-61.

Stalberg, G., Ekerwald, H., \& Hultman, C.M. (2004). At issue: siblings of patients with schizophrenia: sibling bond, coping patterns, and fear of possible schizophrenia heredity. Schizophr Bull 30: 445-58.

Taylor, V., Fuggle, P., \& Charman, T. (2001). Well sibling psychological adjustment to chronic physical disorder in a sibling: How important is maternal awareness of their illness attitudes and perceptions? J Child Psychol Psychiatr Allied Discipline 42:953-62.

Team, R.C. (2013). R: A language and environment for statistical computing.
Tsuang, M.T., Stone, W.S., Tarbox, S.I., \& Faraone, S.V. (2002). An integration of schizophrenia with schizotypy: Identification of schizotaxia and implications for research on treatment and prevention. Schizophr Res 54(1-2): 169-175.

van der Kolk, B.A., McFarlane, A.C., \& Weisaeth, L. (2006). Traumatic stress: the effects of overwhelming experience on mind, body and society. New York: Guilford Press.

van Os, J., Linscott, R.J., Myin-Germeys, I., Delespaul, P., \& Krabbendam, L. (2009). A systematic review and metaanalysis of the psychosis continuum: Evidence for a psychosis proneness-persistence-impairment model of psychotic disorder. Psychological Med 39(2): 179-95.

Vu, V.Q. (2011). ggbiplot: A ggplot2 based biplot. R package version 0.55 .

Westfall, P.H. \& Young, S.S. (1993) Resampling-based multiple testing: examples and methods for p-value adjustment. Wiley, New York.

Wong, F.K.D., Lam, K.Y.A., Chan, K.S., \& Chan, F.S. (2012). Quality of life of caregivers with relatives suffering from mental illness in Hong Kong: roles of caregiver characteristics, caregiving burdens, and satisfaction with psychiatric services. Health and Quality of Life Outcomes, 10: 15.

Xinjun, L., Sundquista, J., Hemminkia, K., \& Sundquista, K. (2009). Familial Risks of Psychotic Disorders and Schizophrenia among Siblings Based on Hospitalizations in Sweden. Psychiatry Research, 166(1): 1-6. 